\title{
Nitrogenase diversity through time and space
}

\section{SAROJ POUDEL AND CORDAY SELDEN}

\section{Rutgers University}

Presenting Author: saroj.poudel@marine.rutgers.edu

Biological nitrogen fixation contributes to roughly two-thirds of the fixed nitrogen on Earth today. The reaction of fixing atmospheric dinitrogen $\left(\mathrm{N}_{2}\right)$ to ammonia is mediated by the metal-containing enzyme nitrogenase. While nitrogenase emerged in an anaerobic chemoautotroph long before great oxidation events (GOE), this oxygen $\left(\mathrm{O}_{2}\right)$-sensitive enzyme complex has since evolved to operate in a variety of genomic and metabolic backgrounds (e.g., aerobes, phototrophs). Despite its known wider distribution, we do not yet have proper documentation of its taxonomic distribution and importantly if there are distinct organisms that encode it. Moreover, if this diversity has any effect on the electron transfer to the enzyme. We studied more than 3000 complete genomes and environmental metagenomes to understand the diversity of the enzyme and how it has evolved. We identified several isoforms of nitrogenase in novel lineages. Several unique environments were found to encode the enzyme that was previously thought to have lacked them. Our analysis also identified distinct pathways of electron transfer to nitrogenase with specific metabolic backgrounds. Together, our work sheds light on the overall ecological distribution of nitrogenase and how it has evolved to function in a diverse environment. 